\title{
Journal of Nursing and Care
}

\section{Outcomes of Thai Emergency Department Patients with Non-traumatic Hypotension}

\author{
Wipa Sae Sia ${ }^{1^{*}}$, Praneed Songwatthana ${ }^{1}$, Tanormsri Pibansak ${ }^{2}$ and Waeyoh Wahama ${ }^{3}$ \\ ${ }^{1}$ Faculty of Nursing, Prince of Songkla University, Songkhla, Thailand \\ ${ }^{2}$ Hat-Yai Hospital, Songkhla, Thailand \\ ${ }^{3}$ Songklanakarind Hospital, Songkhla, Thailand
}

*Corresponding author: Wipa Sae Sia, Faculty of Nursing, Prince of Songkla University, Songkhla, Thailand, Tel: +66-74-286517; Fax: +66-74-6421; E-mail: wipa.sa@psu.ac.th

Received date: May 05, 2018; Accepted date: December 30, 2018; Published date: Jan 07, 2019

Copyright: $\odot 2019$ Sia WS, et al. This is an open-access article distributed under the terms of the Creative Commons Attribution License, which permits unrestricted use, distribution, and reproduction in any medium, provided the original author and source are credited.

\begin{abstract}
Background: The expeditious management of hypotension of emergency department (ED) patients is crucial to prevent hypoxia and in-hospital mortality. This study aimed to identify in-hospital mortality rate, hospital admission rate, and intensive care unit admission rate in Thai ED patients with Non-Traumatic Hypotension (NTH).

Methods: Retrospective chart review of 796 patients with non-traumatic injuries admitted in ED within 3 months in two tertiary hospitals was conducted. A systolic blood pressure less than or equal to $100 \mathrm{mmHg}$ was defined as $\mathrm{NTH}$. A total of 318 (39.95\%) ED records of patients with NTH were retrieved. The main outcome measures were mortality rate, length of intensive care unit stay, and hospital admission rate.
\end{abstract}

Results: The mortality rate and hospital admission rate were significantly higher in NTH patients than in those patients with normative systolic blood pressure. The results of this review study showed that hypotension in ED significantly influenced in-patient mortality $(p=0.002)$ and hospital admission rate $(p<0.001)$.

Conclusion: These findings suggest nurse's work in the ED to provide effective care to restore hypotensive conditions in non-traumatic patients in order to prevent further adverse effects and also reduce the mortality rate.

Keywords: Hypotension; Emergency department; Outcomes; Nontraumatic injury

\section{Introduction}

Hypotension is a known predictor of mortality and morbidity of patients in the Emergency Department (ED) [1-5]. The definition of hypotension varies depending on the diagnosis of the patients. For example, hypotension was defined as systolic blood pressure less than $90 \mathrm{mmHg}$ for patients with trauma injuries [1], less than $100 \mathrm{mmHg}$ for non-traumatic patients [3-5], and less than $110 \mathrm{mmHg}$ for penetrating major trauma patients [2]. It was evidenced that nontraumatic patients attended at the ED with hypotensive conditions in which systolic blood pressure $<100 \mathrm{mmHg}$ were more likely to have sudden and unexpected death (2\%) and intensive care unit admission as compared to those with systolic blood pressure of $>100 \mathrm{mmHg}$ (0.2\%) [4-7].

In the retrospective pilot study, conducted at an urban hospital in Melbourne, Australia, ninety-one ED patients with non-traumatic hypotension were recruited. The results showed that the in-patient mortality rate within this group of patients was $12.5 \%$, and all patients who died had sustained prolonged hypotension, increased length of stay, and prolonged ICU admissions [8]. However, there is no evidence reporting the incidence and significance of ED patients with nontraumatic hypotension, especially in Thai hospitals in urban areas. In addition, it is required to review hypotension in ED patients in Thai hospitals, as no known published study has been found. Such a study can serve as guide to reduce the mortality rate and other adverse outcomes due to hypotension and raise the quality of nursing care.

The purpose of this study was to identify in-hospital mortality, intensive care unit admission, length of hospitalization in ED Thai patients with Non-Traumatic Hypotension (NTH), and to compare those outcomes between NTH and non-traumatic patients with normative systolic blood pressure.

\section{Materials and Methods}

The retrospective study was conducted using two tertiary hospital databases: one from a regional hospital and another from a university hospital in southern Thailand. Approval was obtained from the relevant Ethics Committee before undertaking this study. All patients' records in the ED with NTH were identified as "exposures" whose systolic blood pressure $<100 \mathrm{mmHg}$ on ED arrival $[9,10]$. In this study, normal blood pressure was defined as systolic blood pressure greater than $100 \mathrm{mmHg}$ on ED arrival.

\section{Study settings}

Patients' records from two hospitals were investigated for hypotension status. The first hospital is a regional hospital under the Ministry of Public Health. It is a 700-bed hospital providing care for a large urban population in Songkhla province which also accepts a large number of referrals from nearby secondary and primary hospitals. The 
Page 2 of 4

ED in this regional hospital serves approximately 150-160 patients per day with trauma and non-trauma conditions. The second is an 800 -bed university hospital providing care for both walk-ins and referred patients from hospitals throughout southern Thailand. It is the largest teaching hospital where approximately $180-200$ patients visit the ED per day.

\section{Sample size calculation}

Sample size calculation was calculated based on the percentage of patients admitted to the ED of both hospitals. The average number of admitted patients was $150-160$ patients per day or 4500-4600 patients per month. Approximately, $60 \%-70 \%$ of them were patients with nontrauma related problems. However, approximately $20 \%$ of non-trauma related patients were exposed to systolic BP of $<100 \mathrm{mmHg}$ during their ED care [4]. Essentially, 550 patients were found minimum sample size to serve as a sample of the study.

\section{Data collection and processing}

Data were obtained from the medical records of the patients admitted to the ED every morning. Patients with a blood pressure of $<100 \mathrm{mmHg}$ on admission who were recruited during the previous 24 hours were used for data analysis. Patients also were tracked for hospital admission, intensive care unit (ICU) or ward admission and were followed up until discharge to determine mortality rate and length of ICU stay.

\section{Analysis}

Demographic data of the patients were presented with descriptive statistics. Analyses were performed in SPSS software. The assumption of normality for the length of ICU stay and intensive care unit admission was not met; then, Mann-Whitney $U$ test and Chi-square test were used to examine the differences in outcomes between NTH and normal systolic blood pressure groups. Significant level was set at $\mathrm{p}<0.05$.

\section{Results}

796 cases of patients who met the inclusion criteria within the 3 month study period were recruited. Among the 796 patients, 478 $(60.05 \%)$ had systolic blood pressures greater than $100 \mathrm{mmHg}$ and 318 (39.95\%) presented with systolic blood pressures on admission less than or equal to $100 \mathrm{mmHg}$. The etiology of hypotension was highly related to sepsis or septic shock ( $\mathrm{n}=78,24.53 \%)$. Patients' characteristics and relevant clinical data with hypotension are shown in Table 1.

\begin{tabular}{|l|l|}
\hline Variables & $\mathbf{n}(\%)$ \\
\hline Age $(\mathrm{yr})$ Min=17, Max=93 & \\
\hline $\mathrm{M}(\mathrm{SD})=52.69(20.72)$ & \\
\hline Mdn (IQR) $=52.96(32.04)$ & $154(48.4)$ \\
\hline Gender & $164(51.6)$ \\
\hline Male & \\
\hline Female & \\
\hline Religion & \\
\hline
\end{tabular}

\begin{tabular}{|l|l|}
\hline Buddhism & $289(90.9)$ \\
\hline Islamic & $29(9.1)$ \\
\hline Causes of hypotension & $78(24.53)$ \\
\hline Sepsis/septic shock & $58(18.24)$ \\
\hline Cardiovascular/Circulatory system & $23(7.65)$ \\
\hline Digestive/ Excretory system & $13(4.50)$ \\
\hline Respiratory system & $12(3.78)$ \\
\hline Lymphatic/ Immune system & $10(3.14)$ \\
\hline Reproductive system & $10(3.14)$ \\
\hline Nervous system & $9(2.83)$ \\
\hline Alteration of conscious & $8(2.53)$ \\
\hline Renal/Urinary system & $6(1.89)$ \\
\hline Endocrine system & $5(1.57)$ \\
\hline Pain & $3(0.09)$ \\
\hline Muscular/Skeletal system & $83(26.10)$ \\
\hline Missing diagnosis & $162(50.94)$ \\
\hline Destination after ED admission & $138(43.40)$ \\
\hline Discharged & $48(34.78)$ \\
\hline Admitted & $90(65.22)$ \\
\hline ICU admitted & $18(5.70)$ \\
\hline Ward admitted & \\
\hline Dead & \\
\hline ICU = Intensive care unit & \\
\hline
\end{tabular}

Table 1: Demographic data and relevant characteristics of patients with non-traumatic hypotension $(\mathrm{N}=318)$.

Overall, the mean systolic blood pressure of the sample with $\mathrm{NIH}$ was $92.04 \mathrm{mmHg}(\mathrm{SD}=9.21)$ with a median of $95 \mathrm{mmHg}(\mathrm{IQR}=11)$. Other vital signs are shown in Table 2. Considering the mean systolic blood pressure of patients with sepsis, septic shock, cardiogenic shock, or circulatory problems $(n=138,42.77 \%)$, it was found that the mean systolic blood pressure of both septic and cardiogenic shock was 88.52 $\mathrm{mmHg}(\mathrm{SD}=11.01)$ with a median of $92 \mathrm{mmHg}(\mathrm{IQR}=15)$. Most of the septic shocks were caused by urinary tract infection or respiratory tract infection $(n=65,20.4 \%)$. The hospital admission rate was $43.40 \%$ $(\mathrm{n}=138)$ and intensive care unit (ICU) length of stay was 12.92 days $(\mathrm{SD}=5.07)$ with median of 7.5 days $(\mathrm{IQR}=13)$ (Table 2).

\begin{tabular}{|c|c|c|}
\hline Variables & $M(S D)$ & $\operatorname{Mdn}(I Q R)$ \\
\hline \multicolumn{3}{|l|}{ Blood pressure $(\mathrm{mmHg})$} \\
\hline Systolic $($ Min $=45, \operatorname{Max}=100)$ & $91.94(9.41)$ & $95(11)$ \\
\hline Diastolic $(\operatorname{Min}=22, \operatorname{Max}=86)$ & $56.83(9.96)$ & $57(13)$ \\
\hline Pulse rate $($ beat $/ \min )(\operatorname{Min} 42, \operatorname{Max}=177)$ & $94.42(23.12)$ & $94(32)$ \\
\hline
\end{tabular}


Page 3 of 4

\begin{tabular}{|l|l|l|}
\hline Respiratory rate $(\mathrm{beat} / \mathrm{min})(\mathrm{Min}=18, \mathrm{Max}=56)$ & $25.78(6.38)$ & $24(6)$ \\
\hline Temperature $\left({ }^{\circ} \mathrm{C}\right)(\mathrm{Min}=35, \mathrm{Max}=39.90)$ & $37.15(0.97$ & $37(1)$ \\
\hline ICU length of stay (days) $(\mathrm{Min}=1, \mathrm{Max}=71)$ & $12.92(15.07)$ & $7.50(13)$ \\
\hline
\end{tabular}

Table 2: Blood pressure and other relevant data on ED admission with non-traumatic hypotension $(\mathrm{N}=318)$.

As compared to patients without hypotension whose systolic blood pressure $>100 \mathrm{mmHg}$, it was found that the mortality rate of those without NTH was significantly lower than NTH (1.7\% vs. $5.7 \%)$ $(\chi 2=9.63, \mathrm{p}=0.002)$ and the hospital admission rate was significantly lower than those with NTH $(22.85 \%$ vs. $49.06 \%)(\chi 2=60.80, \mathrm{p}<0.001)$. In addition, the length of ICU stay was lower than that with NTH (Table 3 and Table 4).

\begin{tabular}{|c|c|c|}
\hline Variables & $M(S D)$ & Mdn (IQR) \\
\hline \multicolumn{2}{|l|}{ Blood pressure $(\mathrm{mmHg})$} & \\
\hline Systolic (Min=101, Max=112) & $105.81(2.59)$ & $107(5)$ \\
\hline Diastolic $($ Min=36, Max=96) & $65.94(7.34)$ & $64.5(12)$ \\
\hline Pulse rate (beat/min) (Min 64, Max=172) & $91.43(20.95)$ & $88(30)$ \\
\hline $\begin{array}{l}\begin{array}{l}\text { Respiratory } \\
\text { Max }=60)\end{array} \text { rate } \quad(\text { beat } / \mathrm{min}) \quad(\mathrm{Min}=12 \text {, }\end{array}$ & $23.89(5.87)$ & $22(4)$ \\
\hline Temperature $\left({ }^{\circ} \mathrm{C}\right)(\mathrm{Min}=30.80, \mathrm{Max}=42.40)$ & $37.10(1.14)$ & $36.8(0.90)$ \\
\hline ICU length of stay (days) $(\mathrm{Min}=1, \operatorname{Max}=63)$ & $10.05(13.72)$ & $6.0(7)$ \\
\hline Destination after ED admission & $N(\%)$ & \\
\hline Discharged & $368(77.15)$ & \\
\hline Admitted & $109(22.85)$ & \\
\hline ICU admitted & $43(39.45)$ & \\
\hline Ward admitted & $66(60.55)$ & \\
\hline Dead & $8(1.7)$ & \\
\hline
\end{tabular}

Table 3: Blood pressure and other vital signs on ED admission without hypotension $(\mathrm{N}=478)$.

\begin{tabular}{|c|c|c|c|}
\hline Group & $\begin{array}{l}\text { With } \\
\text { Hypotension }\end{array}$ & Without hypotension & Statistics \\
\hline $\begin{array}{l}\text { ICU length of stay } \\
\text { (Mdn/IQR) }\end{array}$ & $7.5(13)$ & $6(7)$ & $-1.08^{a}$ \\
\hline $\begin{array}{l}\text { Hospital admission } \\
(\mathrm{n} / \%)\end{array}$ & $156(49.06)$ & $109(22.85)$ & $60.80^{\mathrm{b}^{* * *}}$ \\
\hline Mortality (n/\%) & $18(5.7)$ & $8(1.7)$ & $9.63^{b^{\star \star}}$ \\
\hline
\end{tabular}

Table 4: Comparison of hospital length of stay and intensive care unit length of stay between patients with non-traumatic hypotension and those without hypotension.

\section{Discussion}

This study provides the characteristics of $39.95 \%$ adult hypotensive patients who arrived at the ED in two tertiary care hospitals in Southern Thailand. If compared with others who used the same definition of hypotension (systolic blood pressures of $\leq 100 \mathrm{mmHg}$ ), the prevalence of hypotension was higher $(39.95 \%)$ than that of the previous studies (19\%-20\%) [4,9]. In this study, the ED patients with hypotension had no history of trauma. As per the etiology of hypotension, sepsis or septic shock was most prevalent $(24.53 \%)$ in patients with non-trauma injuries followed by cardiogenic shock or cardiovascular problems (18.24\%). However, the prevalence of hypotensive shock in this study was higher than that in a previous study by Holler and colleagues [11] which showed that the ED prevalence of a subgroup of hypotensive shock was between $0.95 \%-1.9 \%$. The difference in prevalence may be because of the difference in the definition of hypotension (using the definition of systolic blood pressure less than $90 \mathrm{mmHg}$ in non-traumatic patients), and of the different etiologies of hypotension.

The mean systolic blood pressure for patients with shock either from sepsis or cardiovascular problems was less than $100 \mathrm{mmHg}$, similar to previous studies $[4,11]$. In addition, it was consistent with another study which showed that hypotensive sepsis of systolic blood pressure $<100 \mathrm{mmHg}$ in the ED patients was associated with higher inhospital mortality compared to patients with sepsis and without hypotension [5].

Similar to the previous study, $18.24 \%$ of NTH had cardiovascular or circulation problems. This study showed that $15 \%$ of ED patients with hemodynamic problems, especially cardiac tamponade, were hypotensive often with systolic blood pressures of $<90 \mathrm{mmHg}$ upon ED arrival [12]. In addition, when comparing the same definition of hypotension with systolic blood pressure of $<100 \mathrm{mmHg}$, it was found that there were $5.7 \%$ of patients with NTH in this current study that died during their ED admission and/or in-hospital admission. This percentage was less than that found in previous cohort studies in which the mortality rate was between $12.5 \%$ [8] to $26 \%$ [3]. These data illustrate that different settings, small sample size, and different patient diagnosis and treatment protocol might influence different mortality rates.

Furthermore, the results of this study showed that nearly half of the patients with NTH were admitted to the ICU (43.40\%) which is similar to a previous Australian study [8]. Additional analysis also showed that the mortality rate and hospitalization admission rate in patients with hypotension were greater than those in patients with normative blood pressure.

\section{Limitations}

This study has some limitations. First, some missing data were encountered because this was a retrospective study. Second, the outcomes of hypotension and non-hypotension in ED patients with traumatic and non-traumatic problems were not compared because of the data of non-hypotension ED patients with traumatic problems of the study hospitals were not explored. Third, duration of hypotension in ED admission was not explored; therefore, outcomes of each subscale of ED hypotension could not be explored in-depth. 
Citation: Si WS, Songwatthana P, Pibansak T, Wahama W (2019) Outcomes of Thai Emergency Department Patients with Non-traumatic Hypotension. J Nurs Care 8: 470. doi:10.4172/2167-1168.1000470

Page 4 of 4

\section{Conclusions}

This study suggests that hypotension in ED impacts in-patient mortality and length of ICU stay. These findings suggest nurses working in the ED should triage non-traumatic patients with a systolic blood pressure $<100 \mathrm{mmHg}$ to resuscitation areas and within appropriately special healthcare providers. Effective triage and management would then restore hypotensive conditions and contribute to reducing mortality rate, hospital admission, and ICU admission. Further prospective studies are needed to provide a better understanding of the duration of ED hypotension and its outcomes, including examining nursing management in ED and care outcomes after discharge from the ED.

\section{Acknowledgement}

The authors would like to thank Prince of Songkla University for providing research funding and also the Research Center for Caring and Healing System for People with Trauma, Emergency, and Disaster, Faculty of Nursing, Prince of Songkla University, Thailand for supporting research assistants for data collection. A special thank is also acknowledged to Publication Clinic, Prince of Songkla University, for editing this manuscript.

\section{References}

1. American Colleague of Surgeons (2014) Resources for optimal care of the injured patient.

2. Hasler RM, Nuesch E, Juni P, Bouamra O (2012) Systolic blood pressure below $110 \mathrm{mmHg}$ is associated with increased mortality in penetrating major trauma patients: Multicenter cohort study. Resuscitation 83: 476-481.
3. Jones AE, Aborn LS, Kline JA (2004) Severity of emergency department hypotension predicts adverse hospital outcome. Shock 22: 410-414.

4. Jones AE, Yiannibas V, Johnson C, Kline JA (2006) Emergency department hypotension predicts sudden unexpected in-hospital mortality: A prospective cohort study. Chest 4: 941-946.

5. Marchick MR, Kline JA, Jones AE (2009) The significance of nonsustained hypotension in emergency department patients with sepsis. Intensive Care Med 35: 1261-1264.

6. Holler JG, Henriksen DP, Mikkelsen S, Pedersen C, Lassen AT (2016) Increasing incidence of hypotension in the emergency department: A 12 year population-based cohort study. Scand J Trauma Resusc Emerg Med 24: $1-13$.

7. Vorwerk S, Ganter K, Cheng Y, Hoheisel J, Stähler PF, et al. (2008) Microfluidic-based enzymatic on-chip labeling of miRNAs. N Biotechnol 25:142-149.

8. Cheng P, Smit D, Considine J, Duke G (2010) Outcome of emergency department patients with non-traumatic hypotension. Australas Emerg Nurs J 13:160-161.

9. Jones AE, Stiell IG, Nesbitt LP, Spaite DW, Hasan N, et al. (2004) Nontraumatic out-of-hospital hypotension predicts in hospital mortality. Ann Emerg Med 43:106-113.

10. Moore CL, Rose GA, Tayal VS, Sullivan DM, Arrowood JA, et al. (2002) Determination of left ventricular function by emergency physician echocardiography of hypotensive patients. Ann Emerg Med 9: 186-193.

11. Holler JG, Bech CN, Henriksen DP, Mikkelsen S, Pedersen C, et al. (2015) Nontraumatic hypotension and shock in the emergency department and the prehospital setting, prevalence, etiology and mortality: A systematic review. PLoS One 10: 1-13.

12. Kapoor T, Locurto M, Farina GA, Silverman R (2012) Hypotension is uncommon in patients presenting to the emergency department with non-traumatic cardiac tamponade. J Emerg Med 42: 220-226. 